\title{
Grasp the Contradictions between Learning and Teaching, Create a Language Environment, and Focus on the Intensive Reading Course
}

\author{
Xuejuan Luo \\ School of Foreign languages, Qinghai Nationalities University, Xining, 810007, China
}

Keywords: Intensive Reading Course, Language environment, Contradictions between learning and teaching, Subject, Guiding

\begin{abstract}
The Intensive Reading Course is a required course in the college English teaching, cultivating students' comprehensive language skills in listening, speaking, reading, writing and translating. It regards mastering the English language knowledge and applications, cross-cultural communication and learning strategies as the main contents, and always adheres to taking the student as the subject. Therefore, it is particularly important to grasp the contradictions between learning and teaching, and to make the students learn the Intensive Reading Course actively and with interest in a harmonious and active classroom atmosphere.
\end{abstract}

\section{Introduction}

The Intensive Reading Course is a core curriculum of college English teaching, what makes it different from the extensive reading is the former one is to teach only the essential and ensure plenty of practice. The Intensive Reading Course not only has the teaching of vocabulary, grammar, functional ideas and basic knowledge, but also has the skill training of listening, speaking, reading, writing and translation. This requires teachers to have a good level of language practice, to make a balance in the classroom, to focus on the key points and difficulties, and to create a language environment with listening and speaking for students in the limited classroom teaching time as mush as possible. At the same time, it needs to consider inspiring the initiative of students, so that the subject and guiding roles of learning and teaching can be played in the greatest degree. Then, how to grasp the contradictions between learning and teaching, to create a language environment and to focus on the Intensive Reading Course are the problems everyone concerned. From many years of teaching practice for me, the contradictions between learning and teaching frequently encountered are:

\section{In Terms of Students}

\section{Insufficient power in English learning}

In teaching, I find that a large proportion of students do not form a strong interest in learning English. In addition to passively accept the learning tasks in the classroom, they rarely spend time to learn English after school. By analyzing the status quo, it can be seen that, for freshmen, the stressful high school learning is under the pressure of entering the university, while the direct power of learning English is to enter to the university. After entering the university, the purpose of college entrance has been achieve, and the new English learning need has not yet formed, so there are a lot of freshmen have an ambiguous sense of learning English. The learning motivations for the students of Non-English majors mainly are external motivations, and the internal motivations are weak. The correct prospective learning motivation takes the leading position, but wrong learning motivation also widely exists, and short-term learning motivation is also common. As a result, the learning initiative for students is poor, and the dependence towards teachers is strong. 


\section{Lack of self-confidence}

Many students, especially the minority students from remote areas, will put most of their energy on learning the basic culture courses in high schools, but only have few time and energy for learning English, and English is their common "weak subject”. Therefore, students are afraid of English from mentally, and they have strong psychological pressures, and poor oral expression abilities. Most of the students will feel headachy, depressed when talking about English, and it seems that English is their "natural enemy". Even some students simply give up learning English. Especially in English Intensive Reading Course, due to the poor foundation, some students cannot keep pace with the teacher's teaching, so they simply fall asleep, and such kind of scenario is common. This makes the English teaching work harder. In a manner of speaking, now the teaching of college English Intensive Reading is in a dilemma: most of the students cannot understand if teaching in English, while it is not accord with the name of English course if speaking in Chinese.

\section{Lack of scientific and effective learning method}

Most students don't know how to reasonably control their learning time, and they are lack of scientific and effective learning methods. In order to pass the CET-4, CET-6, TEM-4, TEM-8, many college students focus on reciting vocabulary and doing sample tests, rather than pay attention to the daily classroom learning and knowledge accumulation. Doing sample tests often spend a lot of time, and the type of test is dazzling. Take the choice question as an example, each question only has one right answer but three incorrect answers, so when the student answer one question, it will input three kinds of incorrect information into the students' mind, so it is impossible to form a correct language sense. And in order to expand the vocabulary, some students simply recite the dictionary, leading to the mechanical memory apart from the context. Therefore, the students will remember today but forget tomorrow, and it spends a lot of time but has a small efficiency, as well as violates the nature of language learning. In addition, currently many students ignore the importance of reading and reciting of English sentences and passages, so they do not have enough language input.

\section{In Terms of Teachers}

Affected by the traditional teaching, most of English teachers are more emphasize on knowledge imparting, while make light of ability cultivating and training. Teachers teach more but students practice less, and the common classroom teaching of intensive reading focuses on the grammar and vocabulary difficulties in the text. The teacher is given priority to explain the text content, and the students passively listen, so it is lack of the training on independent learning and thinking. The teaching emphasis is give priority to analyze difficulties in language and grammar structure, and the teaching mode is the traditional "grammar + translation" without considering the students' learning initiative, enthusiasm and interest, making light of ability training. The students' subjective initiative and thinking creativity cannot be played fully, resulting in the teacher is in anger, but the students are at a loss.

Affected by the conditions, the teaching facilities and teaching methods are unitary, abstract, stylized and lack of language learning atmosphere, which are not good enough to stimulate the students' interests in language learning. The teacher gets used to the unitary classroom form of one boon, one pen and one person alone to teach. Many teachers are not good at using the modern multimedia teaching technologies, and cannot make full use of multimedia to improve the students' interest in learning English. English cannot be used as a language to be applied and experienced, so the students are more lack of the chances to practice English.

Lack of researches in teaching. Due to the teachers have many classes, so they often pay attention to the classes, and have no more time to summarize and research the teaching theories, teaching rules and teaching methods. This is extremely unfavorable to improve the teachers' teaching level and scientific research level. 
In the long-term teaching of Intensive Reading Course, I have explored a set of methods on how to grasp the psychological characteristics, overcome the contradictions between learning and teaching, and create a vivid and orderly language environment. Here, I would like to share with colleagues.

Firstly, as an English teacher, we should constantly consider how to help the students to learn effectively. Obviously, we cannot change the students' personalities, let the shy students to boldly practice English in public and to express their ideas in English without scruple, make them become confident, and make the indifferent students dare to take risks. However, we can think out some ways to help them, to study their personalities, and to know their level of learning, motivation, interests and aspirations. In teaching we carefully design some targeted teaching activities to stimulate students' indirect interests, to promote their learning intrinsic motivation, and to make them have somewhat successful experience in practice. We also should make efforts to build a good classroom atmosphere, to make the poor self-esteem students feel comfortable and satisfied, to let them be inspired in the atmosphere of love and understanding, and to have successful experiences [1].

Secondly, the teacher should strengthen the guidance towards students' English learning methods and the cultivation of learning habits. We should guide the students in terms of preview, review, problem solving and extracurricular materials' reading, so that to cultivated their abilities of self-study. Especially for the disadvantaged students, in addition to make good guidance, we also teach them learning methods and cultivate their good learning habits. The teacher should encourage students to read more and recite more. Ample reading produces fluent writing. The English learning content for college students should not be restricted in the textbook of college English, so they can enlarge the reading scope by reading all kinds of English books in the library. Through the language context located by the author, the understanding of his life experiences, time background and social culture, and his metal state revealed between the lines, the profundity of the works can be felt perfectly[2]. Through a lot of reading and reciting these methods conformed to the rules of language learning, they can achieve greater progress, and can generate keen interests in the process with the deepening of the study.

Thirdly, increase the variables of classroom teaching. Over the years, linguists have been explored the teaching of English from different perspectives, so it has emerged in a number of different teaching theories and teaching methods, such as grammar-translation method, audio-lingual method and communicative method, etc. Nevertheless, any kind of teaching method theory cannot be perfect, so using our own professional judgment to choose the way of teaching and learning, and such way is likely to be the way the students desired [3]. Therefore, in the teaching process, consideration should be given to the learning and living environment of Chinese students, for the teaching language is native language rather than English. According to this situation and teaching materials, the teacher must constantly adjust the variables of classroom teaching, that is to pay a attention to both the language rules and the use of language, and to creatively use different teaching methods to organize each lesson. Specifically are:

1). Background introduction: before explaining a lesson, use three to five minutes to introduce the background knowledge of the lesson, describe the main content, them, story background, characters introduction and grammar points with easy and understandable English sentences, so that the students may have a preliminary understanding of the lesson. In the teaching process of introducing background knowledge, appropriately add some English network resources and knowledge introduction related to the article according to the teaching content, create a real language environment, and stimulate the students' interest in learning.

2). Duty conversation: this is the classroom language activity for students to freely express their daily lives, understanding and feeling of extra-curricular books, interesting and meaningful things happened in their daily communications, and it is about five minutes. The purpose is to help students develop a habit to speak English boldly. Students are willing to speak English, but they are also worried about making mistakes, so the teacher should be patient to help and give encouragement. This step enables the students to practice courage in free expression, to expand vocabulary, to master oral speaking skills, and to create a language environment. For freshmen, the first are doing some 
sample oral trainings, and giving the students a topic to make their own preparations. For sophomores and junior students, they can set topics and answer by themselves.

3). Text dialogue: this is the classroom activity related to the background knowledge of the text, and is a teaching process to examine whether the students have prepared what they learn before a class, and whether they completely understand after learning. Before answering, let students read silently for a few minutes or play the record of the text, so that students can review the text content. Questions should normally include flexible questions, and indeed it is a great debate to cultivate students' oral expression skills. Adopting student-centered and interactive teaching methods and fully giving the autonomy to the students in the activities will have a multiplier effect. Students express their views and ideas, practice speaking, improve the level of understanding, and easily master the text content. Thus, converting the paraphrasing form in the traditional intensive teaching into classroom discussions not only can cultivate students' oral expression abilities, but also can deepen students' understanding of the written language through the actual discussion of students.

4). Text explanation: the text explanation is an important part of Intensive Reading Course teaching. It should adopt piecemeal method, which starts from reading the paragraph by students, and the explanation of paragraph should highlight the key points and difficulties and glance off the general points without any treatment. The specific practices are: slightly practicing key words and sentences, including making verbal sentences and writing some examples on the blackboard, and conducting the dredge of difficult sentences through sentence conversion to change statement. Sometimes, it can identify grammatical relations to conduct sentence translation or explain translation skills. These activities are carried out at the level of sentences, and text explanation should include paragraph questioning, finding topic sentences or summarizing article structures, etc. Such as the article in Unit Five in the First Volume of "Comprehensive English Course" can be summarize as:

a). An average English man is reserved, cold and over modest.

b). An average American is open-minded, inquisitive and hard-working.

When explaining the text, it can intersperse situational dialogue, text questions and answers, dictation practice to run through the entire content, so in the end of the explanation, the students have a comprehensive understanding of the text.

5). Paragraph reciting and text retelling: in order to make the students firmly grasp the language points of the text and the grammatical structure, and to understand the entire content, it requires the students to recite some representative passages and it is very necessary to retell the text by using the key words and sentences.

6 ). The processing of various types of exercises: there are many kinds of exercises with large quantities, so when processing, it should simplify them by cutting out the superfluous and should have emphasis. Such as text understanding, vocabulary, word formation, some only need to answer the question, and some sentences with characteristics and difficulties, and other exercises should be done by the students, and the teacher only give tips appropriately. In the structural exercise, sometimes it is relatively boring, so if the teacher can add unique featured example sentences, it can inspire the spirit of the students and see novelties in the everydayness. The teacher should give tips and supplements in comprehensive cloze translation exercises and individual vocabulary exercises. Such as the prepositions "at, in, on, by" in Unit Six in the First Volume of "Comprehensive English Course", it can add "at home, at school, at work, at college”, "in bed, in hospital, in ink", "on holiday, on business, on duty", "by heart, by accident, by mistake” in blank-filling exercises. In reading, writing exercises contain the imparting of skills and knowledge, but it still has a gap to make students master these skills and make practical uses. In reading exercises, the teacher can appropriately explain difficulties, hint the general ideas, require students to read after school, and examine the effect of exercises by asking questions about the general ideas of the text.

7). Dictation test after school: practice has proved that to conduct dictation test after completing each lesion is an effective method. The content includes: vocabulary, sentences and some characteristic paragraph. Through test, the teacher can timely understand the situation of students to 
grasp the text, but what's more important is to urge students to study consciously and grasp the text points firmly.

As we all know, the Intensive Reading Course is a college English course integrated the comprehensive skills of listening, speaking, reading and writing, and the Intensive Reading Course plays an active and beneficial role in our foreign language teaching, which is evidenced by the practices. In the future, it is still an effective way to learn and master English. The teacher must change the traditional teaching ideas emphasizing on books and teachers, and focus on the subject role of students in teaching, so that to get maximum play the leading and subject role of teaching and learning. Overcoming the contradictions of learning and teaching and creating a good language environment are the key to learn the Intensive Reading Course well.

\section{References}

[1] Mary-Ann Reiss, Help the Unsuccessful English Learners. Translated by Huang Dandan, Foreign Language Teaching.1993, (4).

[2] Liu Chendan. Text Linguistics for Teachers. Shanghai Foreign Language Education Press, 1999.

[3] Translated by Wang Quanliang and Wang Yingjie. Functions of Teachers in the Student-centered Teaching (Jan Tudor), Foreign Language Teaching. 1994, (3). 